\title{
TITLE:
}

\section{ON THE DEVELOPMENT OF THE CIRCULATORY SYSTEM OF THE YOUNG ASCIDIAN, CIONA ROBUSTA}

\section{$\operatorname{AUTHOR}(\mathrm{S})$ :}

Hoshino, Zen-ichiro

\section{CITATION:}

Hoshino, Zen-ichiro. ON THE DEVELOPMENT OF THE CIRCULATORY SYSTEM OF THE YOUNG ASCIDIAN, CIONA ROBUSTA. PUBLICATIONS OF THE SETO MARINE BIOLOGICAL LABORATORY 1969, 17(1): 7-17

\section{ISSUE DATE:}

1969-05-30

URL:

http://hdl.handle.net/2433/175569

RIGHT: 


\title{
ON THE DEVELOPMENT OF THE CIRCULATORY SYSTEM OF THE YOUNG ASCIDIAN, CIONA ROBUSTA
}

\author{
ZEN-ICHIRO HOSHINO') \\ Department of Anatomy, Tohoku University School \\ of Medicine, Sendai, Japan
}

With 6 Text-figures

The studies concerning the disposition of the blood vessels of ascidians have been presented by many investigators, but little has undertaken concerning developmental comparative anatomy of the circulatory system of the ascidian. It is interesting from the view point of comparative anatomy to know whether the circulatory system of the ascidian is comparable with the circulatory system of the vertebrates. To answer the question, the author previously studied the disposition of the blood vessels in the alimentary tract of an adult ascidian.

This paper deals with the development of the circulatory system with concern about the alimentary tract of the ascidian.

\section{Material and Method}

The young ascidians of Ciona robusta, were collected in summer from the fish rearing tank of the Onagawa Fisheries Laboratory of the Tohoku University. One per cent Berlin blue solution was injected into the large ventral vessel or into the large dorsal vessel of the material under menthol anesthesia for two to three hours by a syringe with a sharp glass needle. Immediately after the injection, the material was fixed with ten per cent formalin. Dissection and observations were made under the binocular microscope. The body length as measured is the range from the anterior end of the branchial siphon to the posterior end of the body excluding the proximal peduncular portion, if it is present.

\section{Observations}

Individuals of one $\mathrm{mm}$ in length:

A pair of large ventral vessels are situated on the ventral side of the endostyle.

1) Present address: Marine Biological Station of Asamushi, Tohoku University, Aomori City, Japan.

Publ. Seto Mar. Biol. Lab., XVII (1), 7-17, 1969. (Article 1) 
At the postero-ventral corner of the branchial sac, or at the posterior end of the endostyle, these vessels are formed by the bifurcation of a short trunk, which arises from the abvisceral end of the heart, and then extend anteriorly along the ventral side of the endostyle to its anterior end in a pair of ventral vessels keeping a short distance between them and giving off a few branches to the branchial wall on each side on the way (Fig. 1, A).

A thick vessel, the large dorsal vessel, is found on the dorsal side of the branchial sac. It begins at the antero-dorsal corner of the branchial sac, where the neural ganglion is situated, runs downwards along the dorsomedian of the branchial sac to the middle of the sac, where the anus opens, then goes down along the right side of the rectum, the last part of the intestine, till it reaches the postero-dorsal corner of the branchial sac. From this site it runs further downwards closely along the left side of the esophagus to reach the stomach, where it gives off a few branches to form a coarse network, and the thick main trunk leads finally to the advisceral end of the heart (Fig. 2, A).

Some disordered rows of stigmata are found on each branchial wall. A single atrial siphon is found in this stage, although there are two in the young individuals of a preceding stage of $0.5 \mathrm{~mm}$ in length.

The intestine is divisible into three parts. The first part is a short tube just following the stomach. The second part, the so-called mid-intestine, is a slight swelling of the tube and situated on the left side of the stomach, forming together with the first part a horizontal U-shaped loop with a constriction between the two parts. The distal branch of the loop, namely the second part of the intestine, continues to the proximal portion of the third part, which curves anteriorly. The distal portion of the third part runs straight to the anus closely along the left side of the large dorsal vessel. The anus is situated at the middle level of the branchial sac.

An otocyst and an eye are found on the neural ganglion (Fig. 2, A).

\section{Individuals of 2 to $2.5 \mathrm{~mm}$ in length:}

The interspace between the two large ventral vessels along the ventral side of the endostyle becomes narrower (Fig. 1, B).

Six rows of stigmata are formed and these perforate the branchial wall on each side. The branchial transverse vessels are recognized running across the branchial wall on each side between the large ventral and dorsal vessels. In this stage the transverse vessel has not yet been differentiated into the outer and inner tubules.

Fig. 1. Array of the ventral sides of young ascidians injected with dye to show the development of the large ventral vessel. A, individual of $1 \mathrm{~mm}$ in length; $B, 2 \mathrm{~mm} ; \mathrm{C}, 3 \mathrm{~mm} ; \mathrm{D}, 4 \mathrm{~mm} ; \mathrm{E}, 5 \mathrm{~mm}$. bs: branchial siphon, en: endostyle, vv: large ventral vessel.

Fig. 2. Three earlier developmental stages of the large dorsal vessel shown by dye-injected ascidians, dorsal side. A, individual of $1 \mathrm{~mm}$ in length; $\mathrm{B}, 2.5 \mathrm{~mm} ; \mathrm{C}, 3 \mathrm{~mm}$. br: branchial sac, bs: branchial siphon, dv: large dorsal vessel, es: esophagus, in: intestine, inv: vessels spreading on intestine, ng: neural ganglion, $r$ : rectum, st: stomach, trv: branchial transverse vessel. 

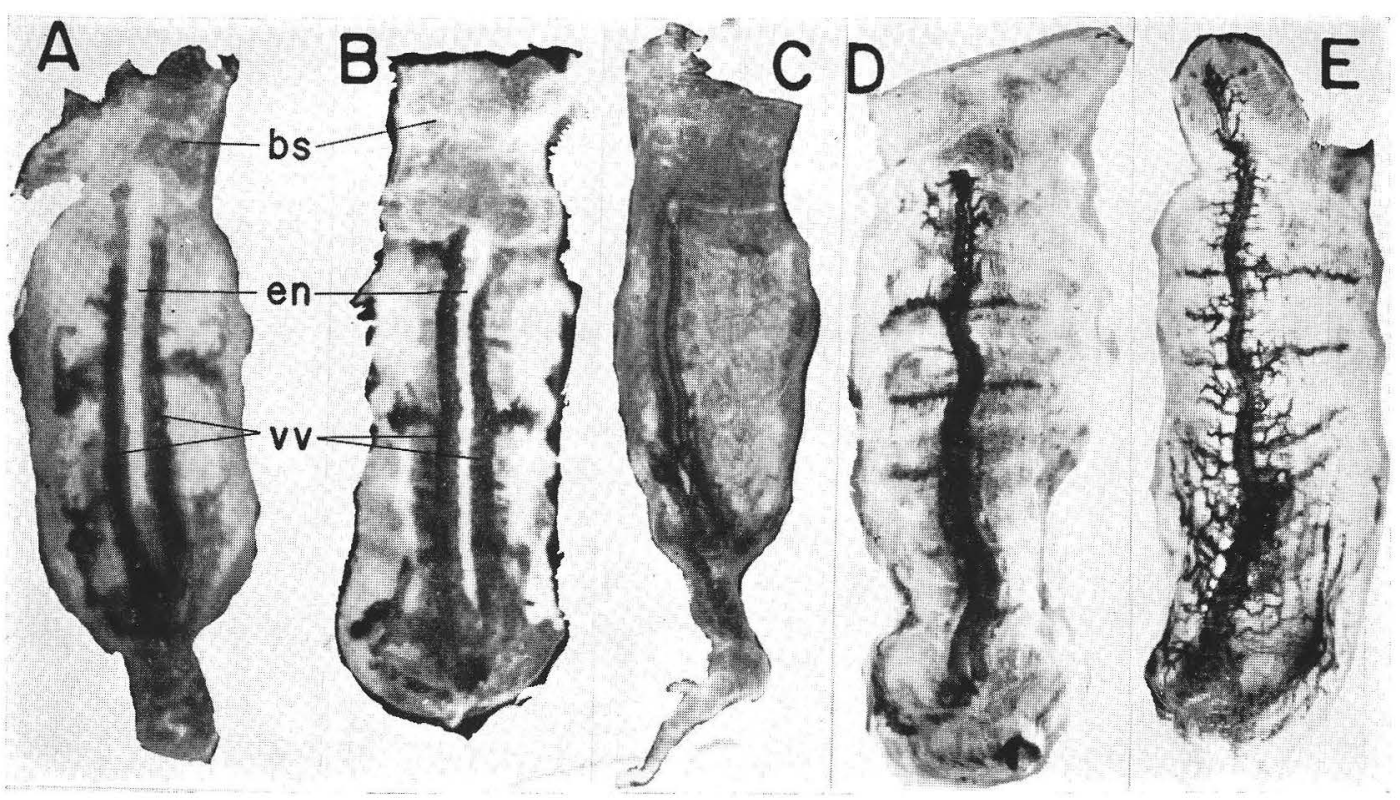

Fig. 1

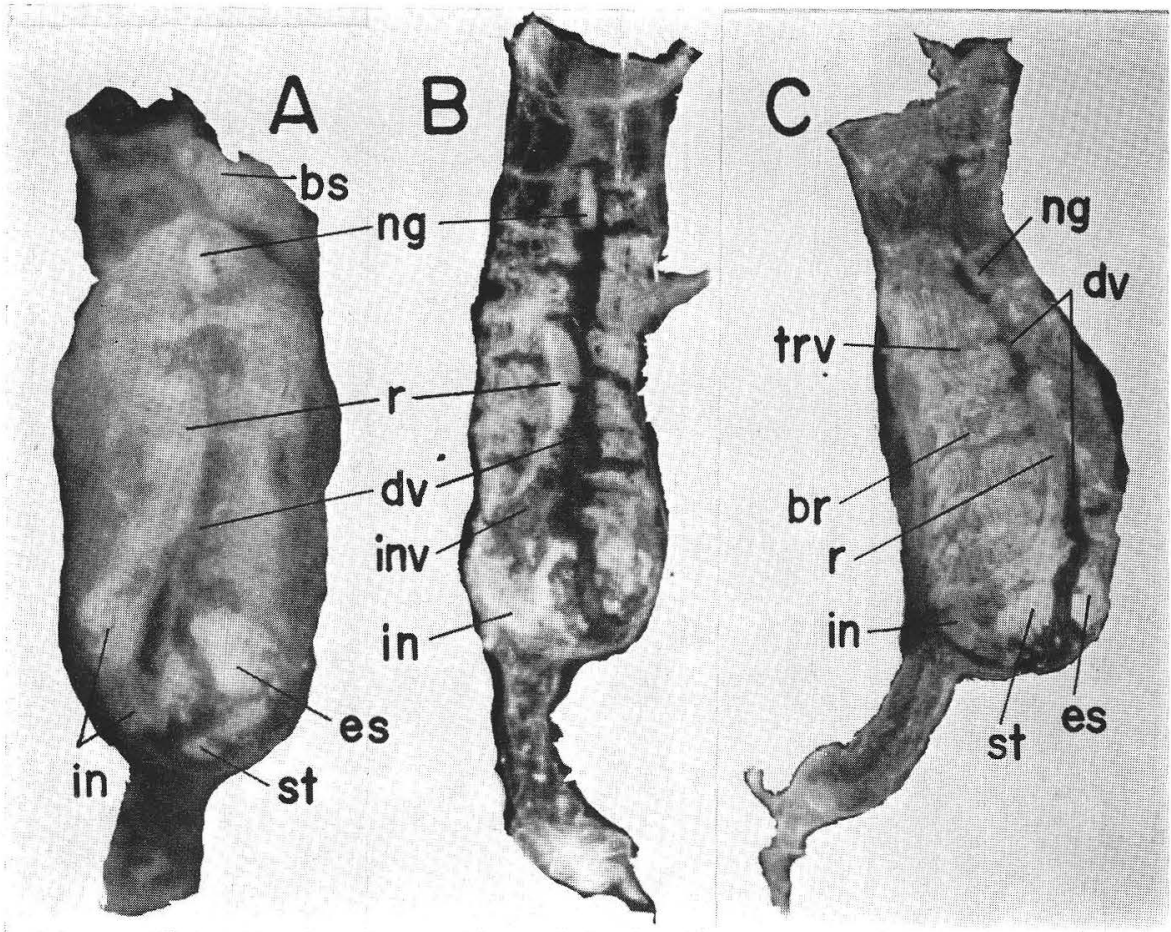

Fig. 2 
Z. Hoshino

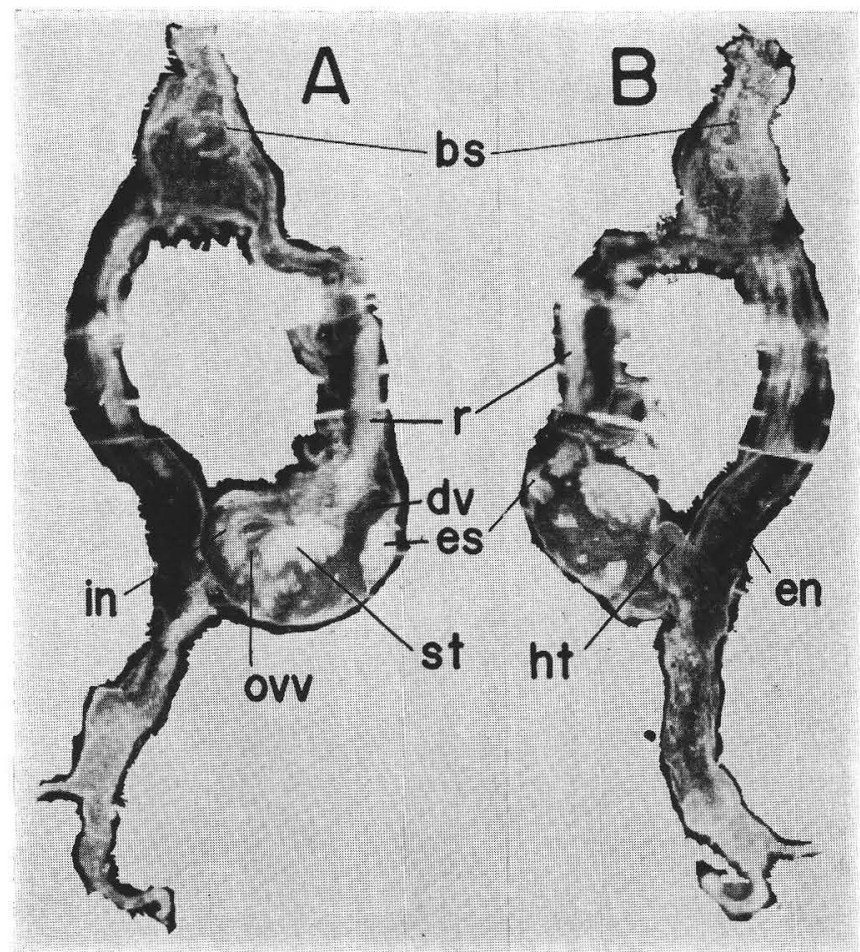

Fig. 3

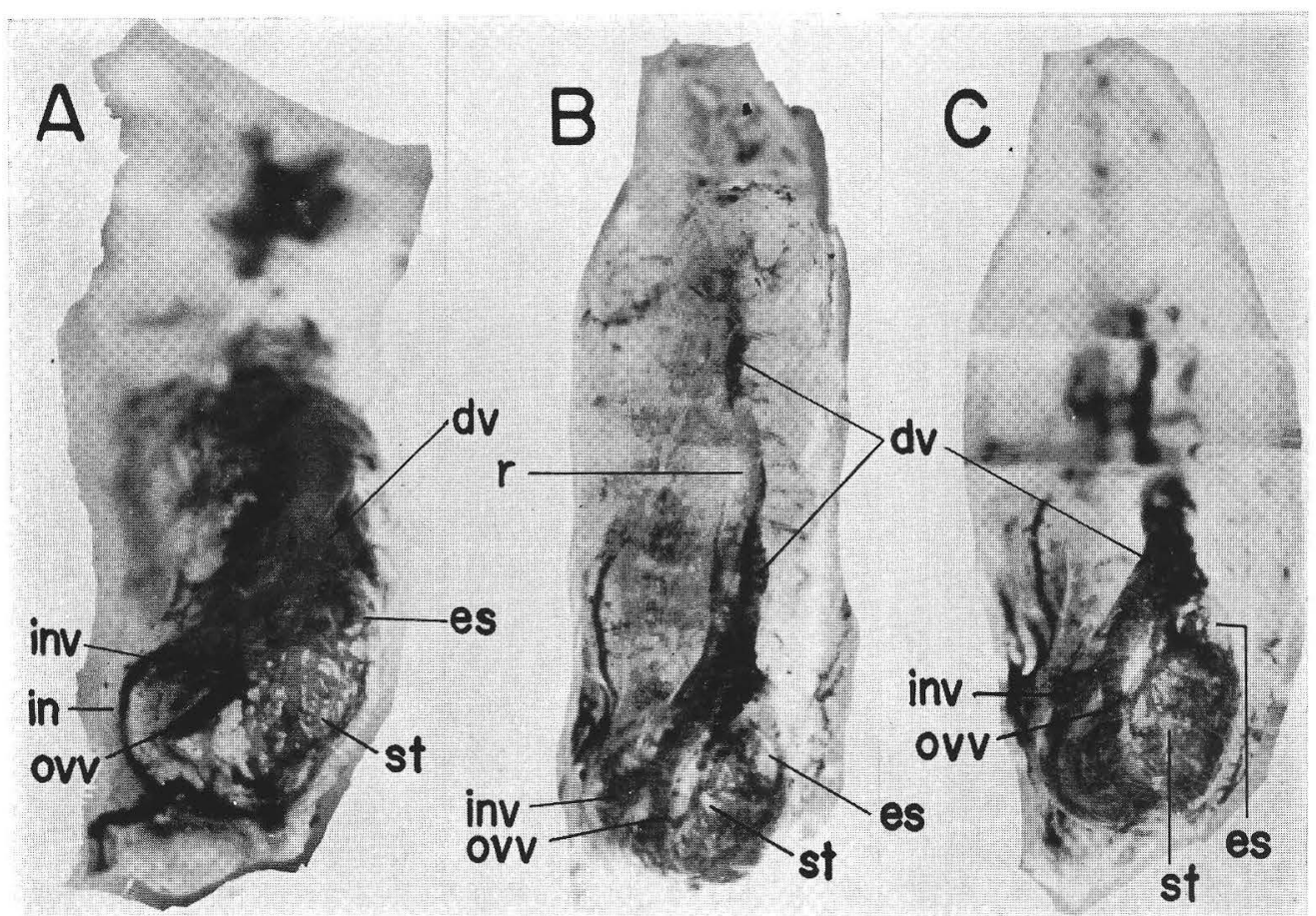

Fig. 4 
The interstigmatic vessels are formed already, but not yet the inner longitudinal vessels. The branchial wall and body wall are connected with each other across the peribranchial space by thin strands at intervals, but no vessels are confirmed in any of these strands by the method of dye-injection.

The main disposition of the large dorsal vessel is much the same as in the case of one $\mathrm{mm}$ long individuals. Namely, the large dorsal vessel begins at the anterodorsal corner of the branchial sac, runs down along the mid-dorsal line of the sac, extends onto the left side of the esophagus, goes around the posterior surface of the stomach, and then reaches the advisceral end of the heart. In this stage a branch arising from the anterior end of the large dorsal vessel is distributed to the dorsal region of the branchial siphon. The trunk of the vessel is partly covered by the distal part of the rectum around the middle of the branchial sac. Near the posterior end of the branchial sac, the dorsal trunk gives off some fine branches which are spread out to form a network on the third part of the intestine. On the posterior surface of the stomach the trunk also gives off several thin vessels to form a coarse network, fine branches issued from which are spread on the first and second parts of the intestine (Fig. 2, B).

\section{Individuals of $3 \mathrm{~mm}$ in length:}

The two ventral trunks have approached each other to become partly in contact at the level of the posterior one third of the endostyle (Fig. 1, G).

There are six stigmatal rows on each side of the branchial sac. Thinner rudimentary transverse vessels are appearing as fragmentary parastigmatic vessels connecting the middle points of some adjacent interstigmatic vessels. Some transverse vessels give off the lateral branches, the so-called dermato-branchial vessels, to the body wall at intervals across the peribranchial space.

The dorsal trunk, which runs down along the mid-dorsal line of the branchial sac, is covered partly with the distal part of the rectum as shown in Fig. 2, C. The trunk vessel is divided into several branches in the stomach region, so that the network of the vessels covers the area wider than in the individuals of the foregoing stage. The fine vessels issued from this network on the stomach surface are now communicating with the partners arising also from the dorsal trunk and being distributed there via the third part of the intestine (Fig. $3 ; \mathrm{A}, \mathrm{B}$ ).

The rudimentary ovary is found in the mesentery connecting the stomach to the

Fig. 3. The large dorsal vessel divided into several branches to form a network of vessels in the stomach region. A showing the left and $B$ the right side of $3 \mathrm{~mm}$ long individual. bs: branchial siphon, dv: large dorsal vessel, en: endostyle, es: esophagus, ht: heart, in: intestine, ovv: vessel passing through ovary, $\mathrm{r}$ : rectum, st: stomach.

Fig. 4. Photographs showing Two developmental stages of the large dorsal vessel shown by dyeinjected ascidians. A: $4 \mathrm{~mm}$ long individual, postero-dorsal view; B, C: $5 \mathrm{~mm}$ long individual, dorsal (B) and postero-dorsal (C) view. dv: large dorsal vessel, es: esophagus, in: intestine, inv: vessel spreading on intestine, ovv: vessel passing through ovary, $r$ : rectum, st: stomach. 

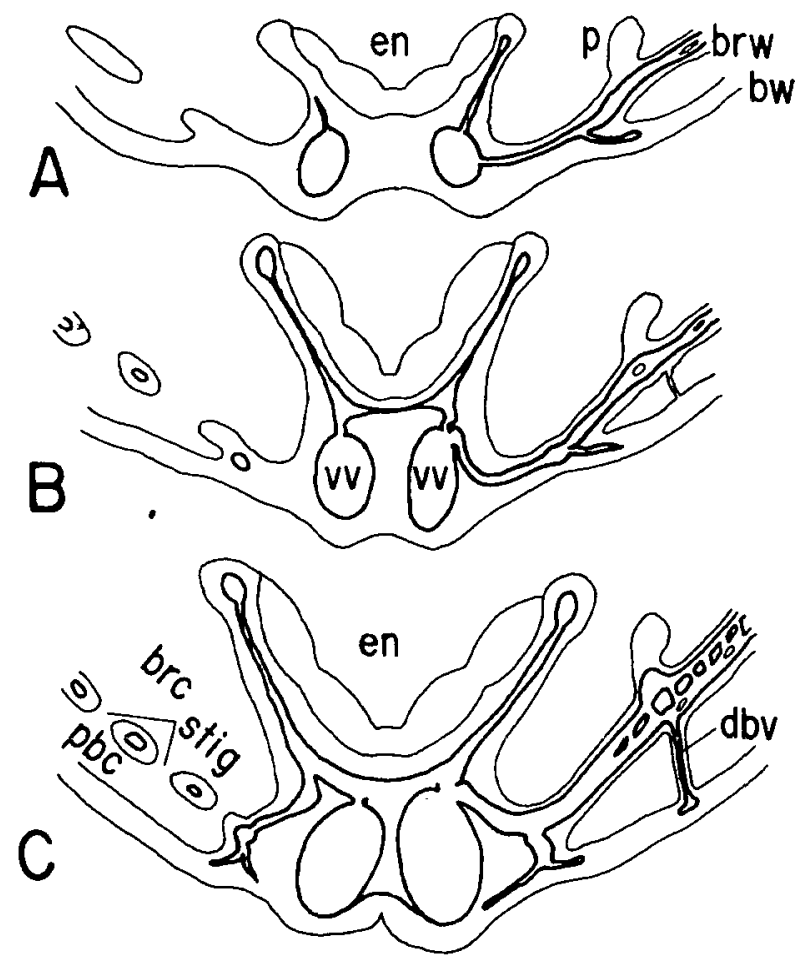

Fig. 5 a. Diagrammatic cross sections of the surrounding region of the endostyle to show the successive developmental stages of the large ventral vessel. A, B, and $\mathrm{C}$ showing the individuals of $1 \mathrm{~mm}, 2 \mathrm{~mm}$, and $3 \mathrm{~mm}$ in length respectively. brc: branchial cavity, brw: branchial wall, bw: body wall, dbv: dermato-branchial vessel, en: endostyle, p: papilla, pbc: peribranchial cavity, stig: stigmata, vv: large ventral vessel.

body wall. On this mesentery, a thin cord, which is the rudimentary oviduct, is extending anteriorly from the rudimentary ovary to reach the intestine. In certain individuals, a thin vessel extends to the rudimentary ovary from the network on the intestine along the rudimentary oviduct. After nourishing the rudimentary ovary, this vessel extends further to the posterior surface of the stomach to join the network in the stomach region (Fig. 3, A).

Individuals of $4 \mathrm{~mm}$ in length:

The two ventral trunks have drawn each other so closely that they are now in contact along their whole length (Fig. 1, D).

The branchial transverse vessel has been differentiated into two, inner and outer, tubules along the whole course, which are connected with each other by short branches 


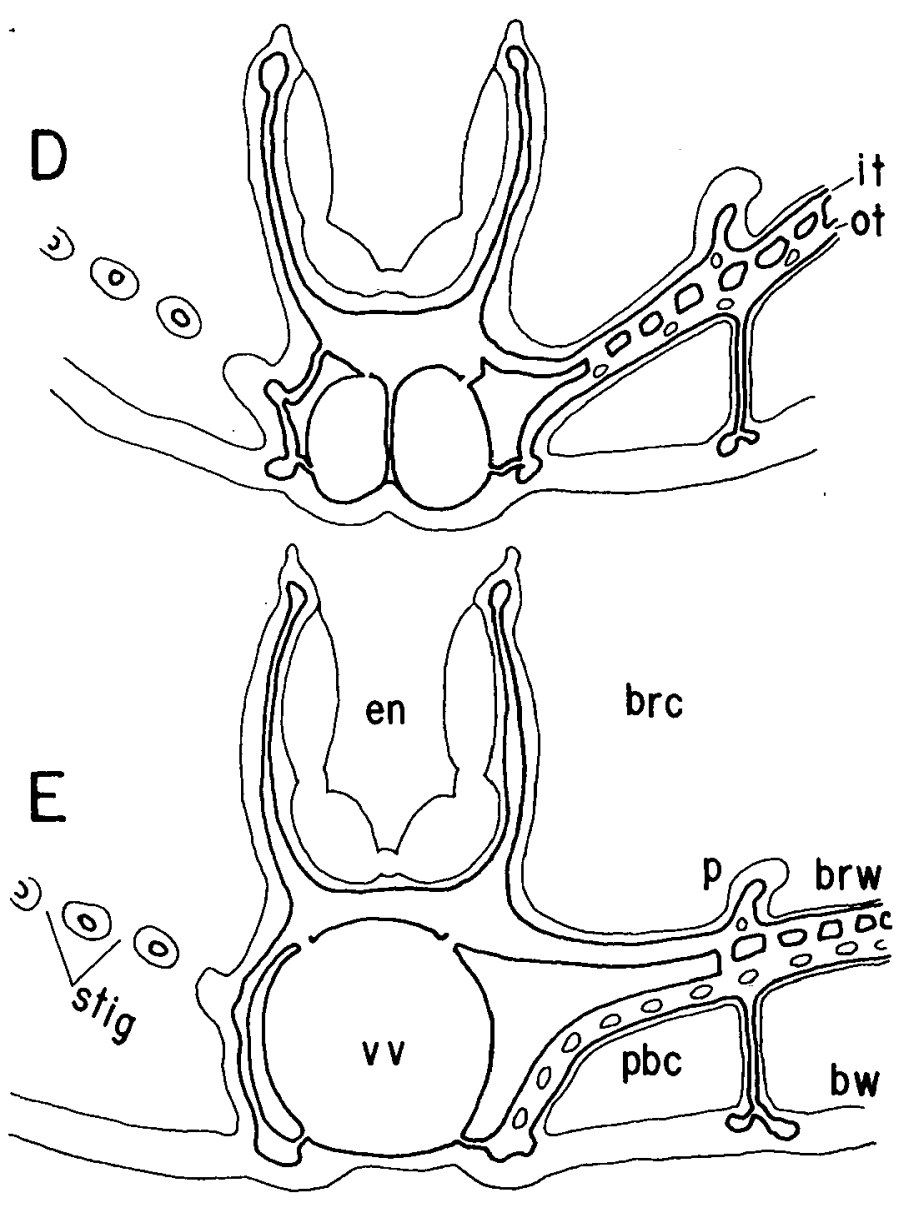

Fig. 5 b. Diagrammatic cross sections of the surrounding region of the endostyle to show the successive developmental stages of the large ventral vessel. $D$ and $E$ showing the individuals of $4 \mathrm{~mm}$ and $5 \mathrm{~mm}$ in length respectively. brc: branchial cavity, brw: branchial wall, bw: body wall, en: endostyle, it: inner tubule of branchial transverse vessel, ot: outer tubule, $p$ : papilla, pbc: peribranchial cavity, stig: stigmata, vv: large ventral vessel.

at intervals.

At the anterior end of the large dorsal vessel a branch is given off. The branch passes by the right side of the ciliary groove to reach the dorsal region of the branchial siphon, while in the younger individuals a pair of branches pass respectively by either of both sides of the ciliary groove to be distributed there. The vessel arising from the large dorsal vessel forms a network of fine vessels on the intestine surface; and a part of the network has developed to a thick vessel running down towards the stomach. Soon after branching off from the trunk vessel, this thick vessel gives off a branch which 


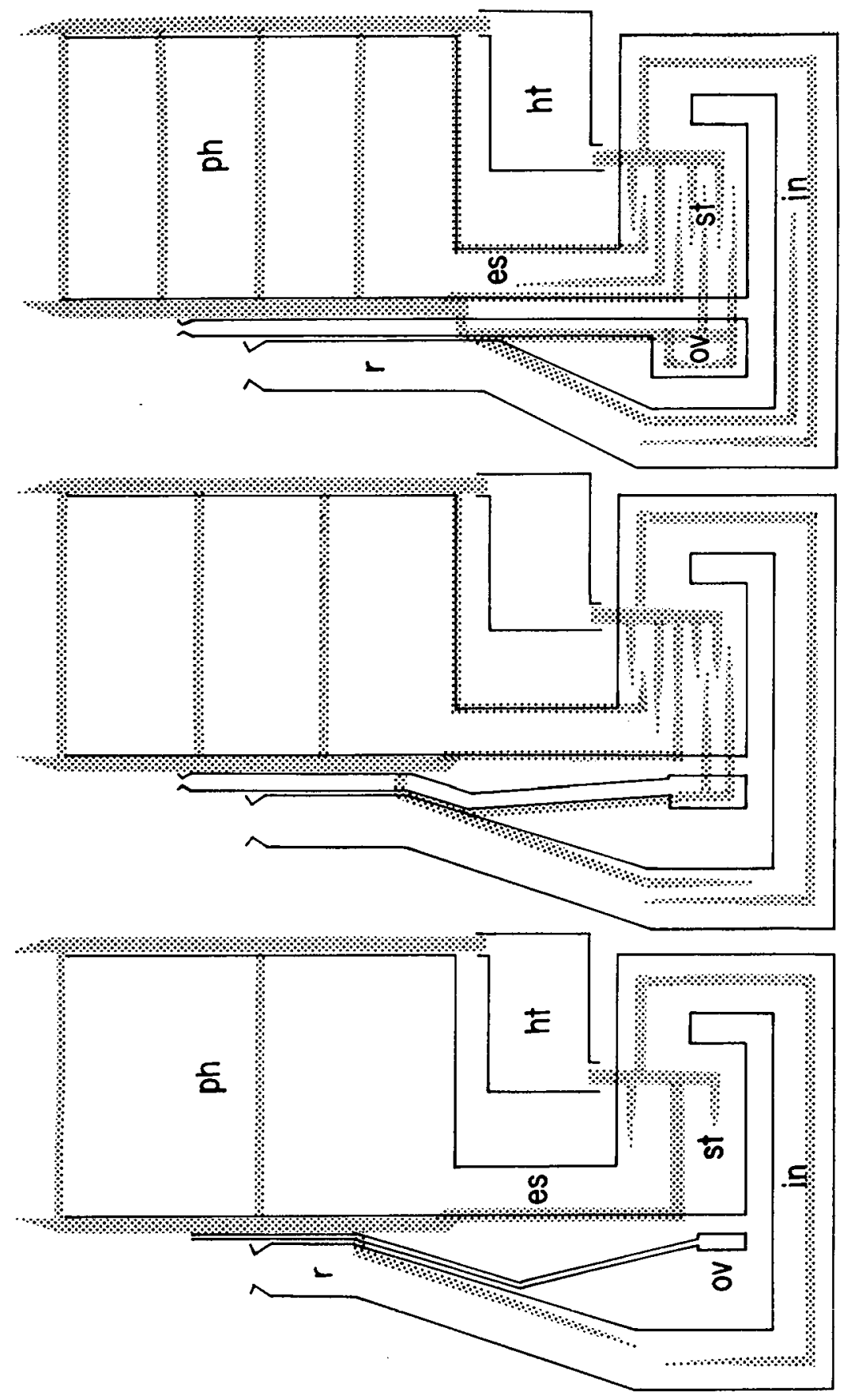

Fig. 6. Schematic diagrams showing the development of the main blood vessels in relation to the alimentary tract of the ascidian, Ciona robusta. The left figure represents a much younger individual, the right represents an adult, and the middle is an intermediate stage between the two. es: esophagus, ht: heart, in: intestine, ov: ovary, ph: branchial sac, $r$ : rectum, st: stomach. 
comes down to the stomach by way of the rudimentary ovary. Before reaching the advisceral end of the heart, the trunk of the large dorsal vessel issues many thin branches to form a network of fine vessels around the esophagus and stomach, some of these branches come down to the esophagus running through the body wall. Although the primary trunk vessel leads still directly to the advisceral end of the heart.

Several vessel branches are derived from the network of fine vessels around the esophagus, stomach and intestine, these then converge on the thick short trunk leading to the advisceral end of the heart (Fig. 4, A).

Individuals of 5 to $5.5 \mathrm{~mm}$ in length:

In this stage, the two ventral trưnks are completely united along their whole length to form a single large ventral vessel (Fig. 1, E).

The transverse vessels connecting the large dorsal and ventral vessels have increased to twenty or more on each side. The inner longitudinal vessels have not been established yet.

The middle one third of the large dorsal trunk vessel is covered by the distal half of the rectum. In this stage, the vessel running along the intestine and leading to the rudimentary ovary takes the place of the main vessel. This main vessel reaches the stomach through a short thick vessel and there it is divided into small vessels. On the other hand, the primary dorsal vessel running posteriorly along the esophagus becomes thin and forms a network of numerous fine vessels in the esophageal region.

The thick vessel running down on the intestine gradually decreases its thickness as it approaches the stomach and communicates with the vessels originated from the network spreading on the stomach.

The network of fine vessels on the stomach is constituted by the anastomoses between the two systems of thick vessels. One of them is the group of vessels derived from the large dorsal vessel and reaching there by way of the esophagus, intestine and ovary. The other is a thick short trunk connecting the advisceral end of the heart with the anastomoses spreading over the stomach (Fig. $4 ; \mathrm{B}, \mathrm{C}$ ).

\section{Discussion}

In the earlier stages, in which the branchial wall does not yet function sufficiently, the blood goes and backs the same large ventral vessels or large dorsal vessel according to the heart pulsation. When the branchial transverse vessels are established, the blood vessel system is completed to make the circuit of the alimentary tract.

In the $1 \mathrm{~mm}$ stage, there are a pair of the large ventral trunk vessels along the endostyle. With further development, the two ventral trunks draw closer to each other to come in contact along their whole length. Finally in the 5 to $5.5 \mathrm{~mm}$ stage, they are united to form together a single large ventral trunk (Fig. 5). This trunk seems to correspond to the truncus arteriosus, ventral aorta, of the vertebrates in its 
relative position to the heart and pharynx, the so-called branchial sac. It is very noteworthy that two ventral trunk vessels are united to form a single trunk.

In the $4 \mathrm{~mm}$ stage the branchial transverse vessel is differentiated into two, inner and outer, tubules along its whole length, while it is represented by a single tubule in the younger stages. It is not clear whether or not the relation between the outer and inner tubules of the branchial transverse vessel is homologous to the relation between the afferent and efferent gill vessels of higher chordates.

In the earlier stages, the large dorsal vessel runs downwards along the middorsal line of the branchial sac, then along the left side of the esophagus, on the posterior side of the stomach, and finally connects with the advisceral end of the heart. With further growth, the trunk of this vessel is divided into many branches to form a network of fine vessels in the stomach region. Accordingly, in the adult ascidian the large dorsal vessel connects with the heart never directly but indirectly through the network of fine vessels spreading in the stomach region (Fig. 6).

It seems possible to consider that the large dorsal vessel belongs to the venous system in the earlier stages, for it connects directly with the advisceral, posterior, end of the heart. But later, the formation of the network of fine vessels in the stomach region makes the property of the large dorsal vessel incomprehensible, because the vessel corresponding to the dorsal aorta has not been identified as yet. It is clear that the large dorsal vessel has developed at first independently of the rectum and intestine, but secondarily acquired a close relation to them as seen in the adult, in which the principal part of the large dorsal vessel is enclosed by the wall of the intestine and rectum.

\section{Summary}

The development of the circulatory system with relation to the alimentary tract of the young ascidian, Ciona robusta, was observed.

In the earlier stages, there are a pair of large ventral vessels which are running in parallel with each other along the ventral side of the endostyle. But, they draw closer to each other with growth, till they are united with each other along their whole length to form a single large ventral vessel.

In the earlier stages, the large dorsal vessel connects directly with the advisceral end of the heart, but with further growth, the dorsal trunk becomes divided into fine vessels spreading on the esophagus, stomach and intestine. These vessels spreading on the viscera are then converged to a short trunk communicating with the advisceral end of the heart. Thus, in the adult ascidian the connection between the large dorsal vessel and the heart is indirect.

\section{Acknowledgements}

The author wishes to express his gratitude to Dr. Isao Motomura, Professor 
Emeritus of the Tohoku University, and Prof. Ryoji URA of the Department of Anatomy, Iwate Medical University, under whose guidance the author's present study was carried out. The author also wishes to thank to Dr. Takashi Tokioka of the Seto Marine Biological Laboratory of the Kyoto University, for his valuable suggestions and encouragement, and Dr. Kiyoshige Sekino of the Fisheries Laboratory of the Tohoku University, for his kind help in collecting the material.

\section{REFERENGES}

Berrill, N.J. (1950): The Tunicata. Ray Society. Bernard Quaritch Ltd., London.

Damas, D. (1900): Les formations epicardiques chez Ciona intestinalis. Arch. Biol., Vol. 15, 1-25. Hoshino, Z. \& T. Toкioka. (1967): An unusually robust Ciona from the northeastern coast of Honsyu island, Japan. Publ. Seto Mar. Biol. Lab., Vol. 15, 275-290.

Hoshino, Z. (1969): A note on the circulatory system of the adult ascidian, Ciona robusta. Bull. Mar. Biol. St. Asamushi, Tohoku Univ., Vol. 13, 255-263.

Seeliger, O. (1893-1911): Bronn's Klassen und Ordnungen des Thier-Reichs. Bd. 3, Suppl. 1. Willey, A. (1893): Studies on the Protochordata. Quart. J. Microscop. Sci., Vol. 34, 317-360. 